\title{
Introduction: Critiquing technologies of the mind: enhancement, alteration, and anthropotechnology
}

\author{
Darian Meacham $^{1,2}$ (D) \\ Published online: 20 March 2017 \\ (C) Springer Science+Business Media Dordrecht 2017
}

\section{Introduction: concepts and challenges in the inflated enhancement debate}

The academic debate surrounding "cognitive enhancement" is now into its third decade. Simply put, the debate concerns attempts, actual and speculative, to amplify and extend "core capacities of the mind through improvement or augmentation of internal or external information processing systems" (Bostrom and Sanberg 2009). Some definitions of cognitive enhancement have sought to constrain the debate by limiting the types of augmenting or extending interventions to contemporary bio- and information technologies. Take for example the definition of cognitive enhancement provided on the website of the Oxford Centre for Neuroethics, one of the central institutional protagonists in the debate: "to extend the abilities of the human mind and to modulate affective and hedonic states through genetic, neuropharmaceutical, computer or direct neural interventions." 1 The epistemological coherence of limiting the definition to contemporary technologies, while discounting other now normalized and ubiquitous ones, for example writing implements, as these definitions do, is certainly suspect and has been heavily criticized (e.g. Buchanan 2011a, b). Elsewhere, I have referred to approaches to enhancement that don't try to limit the concept of enhancement to the use of contemporary bio- or information technologies as "inflationary" (Meacham 2015). An enhancement in the inflationary sense can be defined in the fashion that Buchanan does as "an intervention - a human action of any kind-that improves some capacity (or

${ }^{1}$ See, http://www.neuroethics.ox.ac.uk/research/area 1

Darian Meacham

d.meacham@maastrichtuniversity.nl

1 Department of Philosophy, Maastricht University, Maastricht, Netherlands

2 BrisSynBio, a UK Research Council Funded Centre for Synthetic Biology, Bristol, UK 
characteristics) that normal human beings ordinarily have, or more radically that produces a new one" (Buchanan 2011b, p.5). The inflationary approach does not acknowledge an epistemologically or normatively salient difference in kind between novel technologies (e.g. neuropharmaceuticals, genetic engineering, or neural intervention) and existing, normalized, ubiquitous ones (e.g. pen and paper). This approach, if pushed, seems not only to call into question distinctions between different kinds of technological interventions, but also the distinction between "natural" and technologically mediated or augmented cognitive engagements between and organism and its environment. If we follow the inflationary approach to its limits, there seem to be good reasons to consider some, for example, mnemonic processes involving language that we would normally consider natural, i.e. not technologically mediated, to in fact be technological cognitive enhancements. The justification for this would be that there are good reasons to consider numbers and language itself as technology (Frank et al. 2008). The inflationary approach is particularly significant in the context of this special issue as it opens up the discussion of cognitive enhancement into a broader discussion concerning human relations with technology more generally speaking, and also onto questions of what "normal" cognitive relations with the environment might be. This broadening of the debate finds resonances outside of the frame of Anglo-analytic bioethics and moral philosophy, particularly in areas associated with French Epistemology, Phenomenology and more recently developed sub-fields which draw upon these approaches, namely the methods grouped around the designation 4E-Cognition (enactive, embodied, extended, ecological) (see Menary 2010) - hereafter I'll refer to these as FE-PHEN-4E. The argument that I wish to sketch out here, and which the contributions to this issue support, is that the expansion of the enhancement debate to a broader range of philosophical approaches and methods may help to not only enrich the debate and provide greater philosophical rigor, but also to move it past the current impasse that it arguably finds itself in.

Before proceeding into a discussion of this impasse, it is necessary to point out a further dimension of the debate. We can find this clearly indicated in Hildt's (2013) definition of enhancement: the attempt to "increase cognitive function such as memory or attention in healthy individuals" (Hildt 2013, 1 - my emphasis). This definition describes interventions aimed at a specific capacity or class of capacities (e.g. memory, attention), but requires that, for it to be counted as an enhancement, the individual to whom the intervention pertains must be "healthy". This would imply that an individual with an impaired capacity cannot be healthy. The definition relies on a concept of healthy or normal-functioning capacities. While it is often not clear what concept of health or normality is being used - sometimes it is clear, see, Daniels (2000) - the implied conception seems to be something along the Boorsian biostatistical model of health (Boorse 1977). Kingma (2007) provides a succinct summary of Boorse's position: “According to Boorse's Bio Statistical Theory (BST), health is normal species functioning, which is the statistically typical contribution of all the organism's parts and processes to the organism's overall goals of survival and reproduction. The group with respect to which a contribution is statistically typical is the reference class, specifically an age group or sex or a race of a species." Kingma also convincingly argues that 
Boorse is not able to provide solid grounds for why some reference classes (age, sex, etc.) should be selected over others. Boorse also does not provide an argument either why some functions (survival and reproduction) are the only relevant functions for a theory of health and has been much criticized for this reductionist approach. ${ }^{2}$ Nonetheless, the biostatistical model seems implicitly to be the default understanding of normal health within much of the literature on enhancement, but this definition, entails the augmenting of a capacity or performance beyond or above "normal" reference class functioning. This definition is at least arguably potentially useful insofar as it allows a clear demarcation - important to medical ethics - between medical therapy or treatment and enhancement. Bostrom and Sandberg give a very clear account of how it is generally used in the enhancement literature: "An intervention that is aimed at correcting a specific pathology or defect of a cognitive subsystem may be characterized as therapeutic. An enhancement is an intervention that improves a subsystem in some way other than repairing something that is broken or remedying a specific dysfunction" (Bostrom and Sanberg 2009: 312).

By this account, the aim of a therapy is to restore a capacity or an individual, to return the sick or impaired capacity or individual to a normal healthy state as determined by the statistical norm for the relevant reference class. An intervention that alters the capacity or individual in such a way that they now perform beyond a previous individual or population healthy norm is an enhancement. But such definitions often overlook problems with this notion of normal or healthy; problems which are exacerbated by the concept of enhancement itself. This is particularly important when we speak about cognitive enhancement where conceptions of normality are particularly reliant upon contingent social and cultural environmental conditions. This is precisely the standard critique of Boorse's model. It does not take historical and cultural variations into account concerning what is understood to be normal health. As the French philosopher Georges Canguilhem wrote:

most of the time when speaking of abnormal directions or representations, the psychologist or psychiatrist has in mind as "normal," a certain form of adaptation to the real or to life, one that has no absolute meaning - except, that is, for those who never had an inkling of the relativity of technical, economic or cultural values, who adhere without reservation to the value of these values, and who in the end, forgetting their own conditioning by their surroundings and by the history of those surroundings [... ] show themselves to any thinking even a bit critical to be victims of an illusion very near to what they denounce as madness. (Canguilhem 2008 - my emphasis)

A contemporary example of this is the rise in prevalence of ADHD (attention deficit hyperactivity disorder) in the United States. Without going into detail, it's helpful to refer to psychiatrist Richard Friedman who argues: "People with ADHD may not have a disease, so much as a set of behavioral traits that don't match the expectations of our contemporary culture" (Friedman 2014). Lending more support to the thesis that psychopathologies can be institutionally-socially mediated is the finding that there

\footnotetext{
${ }^{2}$ Thanks to Ruud ter Meulen for this point and for his other comments on the article.
} 
are correlations between geographical discrepancies in the rise of ADHD diagnosis and the implementation of the No Child Left Behind Act in the United States (Hinshaw and Scheffler 2014). ${ }^{3}$ The fact that the psychostimulant pharmaceuticals used to treat ADHD are also the most commonly discussed (both in the media and the academic literature) form of cognitive enhancement for "healthy" individuals makes the technological-institutional structuring of normality and health all the more relevant in the discussion of enhancement.

The inflationary understanding of enhancement further complicates the notion of health or normality. Enhancement within the treatment-enhancement distinction is an intervention that augments or alters a performance or capacity beyond what is deemed normal or healthy, but presumably in a way that is beneficial for the organism. The difficulty introduced by the inflationary concept comes when, as Canguilhem notes, the normal is technologically constituted. In such cases, normal, healthy functioning is dependent upon enhancement technologies that have become normalized or ubiquitous in their use and integration within a certain population. Literacy again serves as a helpful example in relation to cognitive capacity. The inability to use written language as a mnemonic technology is certainly within contemporary modernized society an impairment or pathology (a deviation negatively impacting the individual's ability to function within a specific environment); but its status as such is mediated by the past introduction of an enhancement technology - namely writing and the suite of technologies that surround the practice. The normal or healthy against which the notion of enhancement is distinguished is mediated by enhancement-technology. Bostrom and Sanberg (2009) address this issue of normalized or ubiquitous enhancement technologies by making a distinction between "conventional" and unconventional enhancement. They include education, training, and the use of cognitive artifacts in their account of "conventional" enhancements (312). As Heersmink points out in this issue (Heersmink 2017), conventional for Bostrom and Sandberg means culturally accepted and hence morally unproblematic. But to close off discussion of "conventional" forms of enhancement on the grounds that they are "often well established and culturally accepted" is question begging at best; at worst, it reduces the acceptability of ethical norms to cultural embeddedness or majority opinion. Rather than using the distinction to close off debate concerning "conventional" enhancements, Buchanan does the opposite. He uses the lack of an epistemologically or ethically salient distinction between normal, ubiquitous, conventional enhancements and novel, unconventional, radical enhancement technologies to undermine what he calls arguments against enhancement per se: "The harshest criticisms of biomedical enhancements appear to apply to enhancements per se, whether biomedical or not. [ ...] if we accept that view, we would not only have to reject cognitive enhancement drugs, but must also regard literacy, institutions, and the agrarian revolution in a highly unfavourable light as well." (Buchanan 2011a: 26-27). Buchanan's proposal is to focus on the practical problems raised by specific technologies, but this also defers the conceptual problem that arises

\footnotetext{
${ }^{3}$ The Department of Education (USA) summarizes the No Child Left Behind Act in the following fashion: "The NCLB Act, which reauthorizes the ESEA, incorporates the principles and strategies proposed by President Bush. These include increased accountability for States, school districts, and schools; greater choice for parents and students, particularly those attending low-performing schools; more flexibility for States and local educational agencies (LEAs) in the use of Federal education dollars; and a stronger emphasis on reading, especially for our youngest children" (United States Department of Education 2001).
} 
from the consideration of the relation between the normal and the enhanced. As Bernard Stiegler has pointed out, Buchanan's inflationary concept of enhancement is nearly identical to anthropologist Leroi-Gourhan's idea of hominization as exteriorization: the human is marked by technique; the human struggle for survival is facilitated by the development and utilization of external organs, technologies. Stiegler puts it nicely when he says: "this is the beginning of what is called today the enhancement of the human as the beginning of the human" (Stiegler 2012). Buchanan apparently unknowingly comes very close to Leroi-Gourhan when he writes that not only is "human progress dependent upon enhancement" but that "enhancement has made us what we are - human" (Buchanan 2011b: 24).

We can now parse this understanding of the inextricable link between being a normal human and enhancing oneself through Canguilhem's account of health and normality. For Canguilhem, normality or health is not a statistical concept, but refers to an organism's capacity to successfully respond to the demands made upon it by its environment. Canguilhem plays on Darwin's idea that the most salient aspect of an organism's environment are other organisms; for humans this means that the environment posing demands against which health or sickness will be assessed as states is also a technological, social and economic one. An organism is normal if it can flourish in a given environment, normalcy and health thus pertain to individual somatic and behavioral patterns that the organism adopts in order to respond to the challenges of its environment. Thus, health or normalcy have no absolute meaning for Canguilhem, but are rather an assessment of the relation between an individual organism and its environment. Canguilhem cites René Leriche to make his point: "under the same anatomical exterior one may be either sick or not [...] in itself a lesion does not constitute a clinical disease" (Canguilhem 2008: 130). This entails a relativity of the normal and the pathological from one individual to the next, but within an individual life the experienced difference is absolute. What characterizes pathology in this context is an inability to respond to environmental challenges or shifts in environmental conditions. Canguilhem borrows an expression from the neurologist Kurt Goldstein in stating that the sick individual lives within a "shrunken milieu" which differs qualitatively and experientially from healthy life (132). In his emphasis on the qualitative experience of the individual as the criteria for assessing the distinction between the normal and the pathological, Canguilhem becomes phenomenological in a fashion that we can recognize from Merleau-Ponty's phenomenological descriptions of pathology - for which he drew heavily on Goldstein's studies of pathology and neurological injury. At least for humans, it is the experienced relation between one's self and the environment that is most salient in the distinction between healthy and pathological life. Normal health as contrasting with pathology is not a fixed set of characteristics, but "the capacity to tolerate variations in norms [...] An individual is truly healthy when he is capable of several norms, when he is more than normal. The measure of health is to overcome organic crises and to establish a new physiological order, different from the old" (132). Since the human environment is always a technological environment and since the human individual always extends or enhances itself by way of technology, the capacity to adapt to different demands is likewise nearly always bound up with a technical capacity of the individual.

What has fallen away here is not just the distinction between the normal and the pathological or the normal and the enhanced, but also the absolute distinction between 
all three terms, normal, pathological and enhanced. What has also fallen away is the notion of a fixed environment or set of environmental demands against which the states of normal, pathological and enhanced could be assessed. The technological extension of human life, which allowed it to better adapt to changing environmental demands also lends additional technological precariousness to health. A human being experiences health, in part, by mustering the technical capacities to respond to challenges posed by a technological-institutional environment. Humans must enhance themselves to feel normal. But a continuously changing technological-institutional environment and its correlative demands require that the organism also be continuous in technologically enhancing itself lest it fall into a pathological state by being unable to meet the technological demands of its human-made technological environment. The case of ADHD diagnosis and prevalence in the United States is an example of this. A change in the technological environment facilitates the emergence of the pathology that is named ADHD - a set of behavioral characteristics which might have been advantageous in another environment - a further change in the technological milieu, the introduction of the No Child Left Behind Act is hypothised to have raised the prevalence of the pathology, which is experienced as an incapacity to function well within certain technological environments. A social choice is then made between alteration of the environment and alteration of the affected individuals, primarily school age boys. The requisite further technological alteration to the individual is, in this case, made via psychopharmaceutical inventions which purportedly improve the experience of the individual and its capacity to respond to challenges within the relevant environment. Other individuals who do not manifest the maladaptation to the specific technological environment may also use the same enhancement technology to further improve their capacities within that environment. It is arguable that in both cases the desire to enhance is motivated by an experience of lack or to use Goldstein's term, a "shrunken milieu" which can itself be described as pathological, even if it is not always medicalised.

An environment in which some individuals are deemed to have pathologies due to inadequate capacities to adapt to technical change may also itself shift, expanding or reducing the experience of pathology that creates the demand for enhancement. If for example, an individual is not able to meet the demands posed by a particular working environment without the use of an enhancement, a pathology is in this sense created. In this sense, due to a form of enhancement technology 'lock-in', the possibility arises that while a technology may improve individual performances on the individual level, at the social or environmental level it also creates technologically mediated pathologies that subsequently lead to experiences of limitation or "shrunken environments" not gains in autonomy. This is not a question of a gap opening up between the "normals" and the enhanced, as is often discussed in the literature, but of the creations of new pathologies through the emergence of new technological environments which place new sets of demands upon individual organisms.

In almost any contemporary work environment the use of language and writing technologies is required. Illiteracy can be understood both as a kind of pathology and a lack of a certain technological enhancement in such environments. In most social environments where this is the case, literacy technology is readily available, in the form of public education to nearly the entire population. This particular enhancement technology was a social invention that was designed to allow individuals to meet the 
demands of new (industrial) working environments that emerged in Europe in the nineteenth century (estimated illiteracy rates for English men dropped from about $40 \%$ to less than 5\% between 1800 and 1900) (Mitch 2004: 344). One could likewise envision a situation where a particular social or work environment places a demand upon the individual that is best met through the intervention of psychostimulant pharmaceuticals. An inability (or unwillingness) to adopt this enhancement then becomes pathological within that environment. Thus a distinction remerges, not between the normal/healthy and the pathological but between the pathological and the enhanced. What falls away is the concept of the normal. What I think is key to fruitful engagement in the enhancement debate is the understanding that this dynamic is itself technologically-institutionally mediated. The environment that creates the demand for technological enhancement of human capacities is not a natural given, but is itself the result of processes of technological enhancement cum development. It is our engagement in and with these environmental conditions that determines the openness and health or closure and pathology of our relation with it. As Canguilhem writes: "in a sense there is no natural selection in the human species, to the extent that man can create new milieus instead of passively submitting to changes in old ones. And in another sense, selection in man has reached the limit of perfection, to the extent that man is the living being capable of existence, resistance, as well as technical and cultural activity in all milieus" (Canguilhem 2008: 128).

What I have tried to show through this initial discussion of the concepts and challenges facing the enhancement debate is that the concept of enhancement if taken in its inflationary sense, which I think it should be, does not slide neatly into the relations between the normal/healthy and the pathological, it fundamentally alters these relations to the extent that the distinction itself becomes suspect. Moreover, the relation that I have argued emerges in its stead, that of the pathological and the enhanced, is mediated by environmental relations with technological artifacts that mediate and facilitate our human capacities. Most relevant in the current discussion are those technological artifacts classed as cognitive artifacts - artifacts made for the aim of altering human cognitive capacities. Finally, this mediate relation between the always technologically enhanced human being and its technological environment should be analysed phenomenologically, in terms of how it is experienced by individuals, and particularly in terms of the experiences of openness and closedness of the environment and the possibilities that it presents to individuals. These analyses and indeed I think the future fruitfulness of the enhancement debates, which currently are at an impasse, require drawing on aspects of what I called above FE-PHEN-4E.

\section{Impasse in the debate}

Having staked a position vis-à-vis the main concepts of the debate from a FE-PHEN-4E perspective, let me briefly take a step back to better situate the current state-of-the-debate concerning cognitive enhancement in both its academic and media/public dimensions. Discussions of cognitive enhancement are part of a wider debate, playing out largely within the fields of bioethics, Anglo-analytic moral, and (to a lesser extent) political philosophy concerning "human enhancement" or human technological enhancement. This broader debate, concerning "the intentional effort to improve individuals' performances with the 
help of technical biomedical interventions has mainly centered on contrasting characterizations about either moral [and political] legitimacy or technical plausibility" (Arnaldi et al. 2016, 34). ${ }^{4}$ I do not think it too gross of an oversimplification to say that these debates concerning enhancement in general and cognitive enhancement in particular have to a large extent stalled. As Brenninkmeijer and Zwart (2016) neatly catalogue, "the same set of arguments tends to be raised over and over again. The ethical debate basically revolves around core themes such as authenticity, autonomy, safety and effectivity; competitiveness, and equity," with proponents and detractors of enhancement continuing to talk past each other; the former arguing for the social and individual benefit to be gained from continued efforts to boost cognitive capacity through technological intervention, and detractors arguing that such efforts present a threat to social, political, and human psychological equilibriums, that are in turn often founded in either vague conceptions of human nature or value-laden accounts of the human condition. It does not seem overly pessimistic to say that, with some notable exceptions, the discussion remains polarized by the same bifurcation between "bioconservatives" and "transhumanists" that has characterized it since its inception.

The stalled academic debate is accompanied by a continued media interest in cognitive enhancement, which has a likely feedback effect on the academic debate. At least up to 2012, cognitive enhancement was the most commonly mentioned neuroscience topic in media discussion (O'Connor et al. 2012). Perhaps due to sustained media attention on a handful of questionable surveys claiming to show a high prevalence of off-label clinical psychostimulant use at elite universities, the enhancement debate in both its media and academic settings has, to a large extent, focused on existing means of and future possibilities for psychopharmaceutical enhancement. Thus, while the academic debate seems mired in a kind of normative deadlock, the media debate continues to generate the impression that the normative question itself has been surpassed by events. In 2015, The Guardian newspaper confidently asserted that modafinil, a more or less readily available wakefulness agent used clinically to treat excessive somnolence and widely touted for its apparently rising off-label use, is the "world's first safe smart drug" (Thomas 2015). The owl of Minerva continues to flap its wings at dusk, while reality has already purchased a blister pack of generic modafinil and gone on a productivity bender. However, there remain many outstanding questions about the use, efficacy, and safety of available neuropharmaceutical technologies (see ter Meulen et al. 2017 for a fair and balanced account of the efficacy and risks of modafinil and other psychostimulants). Continuing with the example of the media favourite, modafinil, there is not yet conclusive clinical evidence of its efficacy as an enhancer for individuals without an acute (e.g. sleep deprivation) or chronic cognitive (e.g. ADHD) disability. A recent review points to difficulties in evaluating efficacy (Battleday and Brem 2015):

We found that whilst most studies employing basic testing paradigms show that modafinil intake enhances executive function, only half show improvements in attention and learning and memory, and a few even report impairments in divergent creative thinking. In contrast, when more complex assessments are

\footnotetext{
${ }^{4}$ The use of the term "biomedical" in this definition is rather standard, if not particularly helpful as it seems to simply pertain to an intervention that somehow impacts the human body, thus not ruling out the class of external cognitive artifacts that are clearly included in both the "Oxford" definition, Bostrom and Sandberg's and Buchanan's.
} 
used, modafinil appears to consistently engender enhancement of attention, executive functions, and learning.

Moreover, literature also points to risks of dependency (Ledford 2009) and paranoia (Jerry et al. 2016), as possible side-effects of the drug. This incidentally does not stop newspaper science editors from running headlines to the tune of "'Smart drug' taken by one in four students really does boost performance" (Knapton 2015).

What to make of this? Both the academic-normative and media-empirical (which largely ignores the academic-normative) debates seem mired in bifurcations. ${ }^{5}$ Further, there seem to be parallels in the bifurcations. In their assessment of the "Mutual Learning Exercises" 6 conducted as part of the European Commission FP7 funded NERRI (Neuro-Enhancement: Responsible Research and Innovation) Project, Brenninkmeijer and Zwart (2016) observe what they call a trivialization of the enhancement debate: a reduction of the discourse to considerations akin to whether modafinil, or whatever will take its place, is qualitatively different in a normative or epistemological sense from commonly used substances like caffeine; and polling of how many university students or financial service workers are augmenting their attention spans with off-label use of psychostimulants. ${ }^{7}$ This "trivialization" is coupled with the ongoing deadlock between so-called transhumanist proponents of enhancement, soothsayers of past and future cyborg-humanity, and human condition conservatives.

In addition, as the major safety anxieties surrounding pharmaceutical cognitive enhancement concern the as of yet relatively poorly understood long-term side effects of regular usage, a media debate obsessed with finding "safe smart drugs" has nowhere to go but in circles. In short, there is too much of the should and how of cognitive enhancement, and perhaps too little of the what. What that what is and how we might go about better investigating it is the subject of this introduction and special issue.

In their analysis of the NERRI project findings Brenninkmeijer and Zwart (2016) suggest that one way out of this impasse is to shift the debate away from discussions of students or other professionals (scientists, truck drivers, pilots, finance sector

\footnotetext{
${ }^{5}$ I refer here to the "media" debate rather than the "public" debate. As Fritz et al. (2013) point out, there has not been a great deal of public consultation or study of public attitudes toward cognitive enhancement, despite the high level of media attention and calls for public debate. Fritz et al. (2013) carried out experiments with contrastive vignettes "in order to obtain quantitative data on public attitudes towards cognitive enhancement." However the focus of these experiments remained largely within the standard framework identified by Brenninkmeijer and Zwart (2016) above: safety, equity, authenticity. Fritz et al. also examined pressure to use enhancement technologies as a salient ethical issue. They report that "the data collected suggest that the public is sensitive to and capable of understanding the four cardinal concerns identified by neuroethicists, and tend to cautiously accept cognitive enhancement even as they recognize its potential perils. The public is biopolitically moderate, endorses both meritocratic principles and the intrinsic value of hard work, and appears to be sensitive to the salient moral issues raised in the debate." By contrast a study published by the Funk et al. in 2016 found that majorities (69\%) of U.S. adults say they would be "very" or "somewhat" worried about the use of "brain chips implants" for cognitive enhancement (Funk et al. 2016).

${ }^{6}$ Mutual Learning Events (MLEs), a widely used method in European Commission Framework Programme funded "Science in and with Society" project, "aim to bring together various groups of stakeholders (researchers, users, intermediaries, professionals, students, media, broader publics) to facilitate a mutual learning process through mutual exposure of views and experiences, expectations and concerns" (Zwart et al. 2015: 9, cited in Brenninkmeijer and Zwart 2016).

${ }^{7}$ As Zohny (2015) points out, "the prevalence rates of these drugs are far from clear, with the bulk of the claims resting on poor or misrepresented data."
} 
employees, etc.) taking psycho-stimulants on the one hand and radical cyborg futures on the other, and focus on what they call the "soft-enhancements" offered by a particular class of cognitive artifacts, namely non-invasive brain stimulation devices. The move toward contextualized analysis of cognitive artifacts and away from the existing, ossified debate is welcome. The use of cognitive artifacts for enhancement purposes is certainly much more prevalent than the use of psychopharmaceuticals, to the extent that it is normalized and ubiquitous, examples including navigation systems, diaries, diagrams, calculators, scale-models, timetables, textbooks, and computing devices" (Heersmink 2017; 2014). Yet as Heersmink (2017) points out in this issue, "there is little, if any, talk of moral aspects of enhancing our cognitive abilities with external artifacts," which is odd considering the extensive debate about the moral aspects of psychopharmaceuticals. A likely reason for this is that the ubiquity of enhancing cognitive artifacts may obfuscate or even bring into question their status as enhancers. This perplexity in the debate augments calls for greater conceptual clarity concerning key terms and phenomena related to cognitive enhancement, but also a closer look at the experience/phenomenology of enhancing technologies, particularly in relation to experiences of illness. Philosophical approaches informed by FE-PHEN-4E refocus of the debate on the what that I referred to above as missing.

\section{Broadening the debate}

Given the abundance of resource in the above-mentioned philosophical approaches for addressing the enhancement debate, it is curious that it has remained confined largely, though by no means exclusively, to Anglo-analytic bioethical and moral philosophy. The debate in bioethics has been more international in its scope but still draws remarkably little on non-Anglo-analytic philosophical resources. The most notable exception to this has been Habermas's short intervention concerning genetic alteration, The Future of Human Nature (Habermas 2003), which was met primarily with puzzlement and dismissal by bioethicists interested in enhancement on the grounds of unjustified claims of genetic determinism and essentialism about human nature (see for example Fenton 2006; Buchanan 2011a). ${ }^{8}$ Nor has there been a lack of interest in this debate outside of Anglo-analytic bioethical and moral philosophy, Jérôme Goffette's Naissance de l'anthropotechnie (Goffette 2006) and Jean-Michel Besnier's Demain les posthumains (2010), stand out as exemplars of the enhancement debate outside of the Anglo-analytic context, but there is little if any cross-border engagement on the topic. Goffette suggests a re-working of the treatment-enhancement distinction such that the restorative aims of medical-technē are distinguished from what he calls "anthropotechnie" or "le bricolage de l'humain" - technological tinkering with the human body with the aim of somehow improving in a broader sense than enhancement narrowly and functionally conceived, thus including, for example, cosmetic surgery

\footnotetext{
${ }^{8}$ Habermas (2003), rather than appealing to either discredited essentialist ideas about human nature or genetic determinism, sought to make what he called an "almost transcendental" argument concerning the conditions of possibility for human autonomy. Practically, he was concerned with the threat to autonomy posed by technological control across generations. This more nuanced argument went largely unnoticed in the reception of his intervention, though Buchanan (2011a) does discuss it briefly and dismisses it as the worst kind of armchair philosophy.
} 
and tattooing, which have an aesthetic if not always narrowly functional value under the umbrella of anthropotechnie. Allouche (2015) suggests a revision to Goffette's schema. Rather than make a division between medical interventions and anthropotechnie, she suggests using anthropotechnology as the umbrella descriptive concept under which intentional technological alterations to the human body can be classified. Technologies which aim to restore an individual or population norm could be considered medical, while those that aim at augmenting capacities beyond the scope of medical intervention could be evaluated as enhancements or not depending on their context specific impact. The title and theme of this issue stem from Allouche's schema.

There may be a further reason for a lack of explicit engagement in the enhancement debate on the part of FE-PHEN-4E philosophers. The set of theoretical problems that the enhancement debate often takes for granted, the constitution of the normal, the integration of technological objects into the cognitive, affective, and motile processes of the lived-body, have long been the explicit focus of philosophers working in FEPHEN-4E, as was hopefully in part demonstrated in the first section. If it's the case, as Heersmink points out in this issue, that philosophers concerned with enhancement rarely discuss cognitive artifacts, the reverse is not true. Clark and Chalmer's seminal paper, "The Extended Mind" (Clark and Chalmers 1998), is but one important example of how the discussion of extended cognition and cognitive artifacts has always been, at least implicitly, a discussion of the epistemology of cognitive enhancement. Likewise, it is easy to point to normative discussions in the philosophy of technology that are concerned with human-technology relations, and in particular the technological extension of cognitive capacities, which also draw heavily upon and engage with FE-PHEN4E approaches (Kiran and Verbeek 2010 is one such example). As Walsh notes in this issue, there are also ample instances of philosophers who have noted the important relation between the theory of extended cognition and cognitive enhancement, (Buller 2013; Clark 2007; Heersmink 2011, 2013; Levy 2007).

In this issue, Heersmink (2017) addresses three aspects of cognitive artifacts that are particularly relevant to the moral dimensions of the cognitive enhancement debate. These are the consequences for brain processes, cognition and culture; the moral status of cognitive artifacts themselves; and, finally, the way that cognitive artifacts may impact the formation and maintenance of personal identity. On the first point Heersmink points out that human-machine hybridization is by no means an intrinsic good. Artifacts are value-laden, but also transform experience and can have unintended consequences. One example of the latter being the apparent de-skilling that accompanies prolonged frequent use of navigational systems such as Google Maps. Technologies transform the brain and characteristics of cognition. This makes phenomena like cognitive offloading not only epistemologically but also morally salient: we need to be able to assess the benefits and losses at individual and social levels that may stem from these transformations.

It is important to point out that there is by no means uniformity of approach or agreement in what I've called the FE-PHEN-4E approaches. Case in point, in this issue, Walsh (2017) questions the functionalist approach to cognition that permeates not only much of the Anglo-analytic cognitive enhancement literature, but also the literature on cognitive extension and artefacts. He argues that the functionalism of these approaches may make them less able to recognize some of the transformations of subjective experience that the increased distribution of cognition into artifacts engenders. This 
commitment to functionalism in accounts of cognition on the bioethical and moral philosophy side of the enhancement debate is well illustrated by Bostrom and Sanberg (2009). They define the core aspects of cognition as: "the processes an organism uses to organize information. This includes acquiring information (perception), selecting (attention), representing (understanding) and retaining (memory) information, and using it to guide behavior (reasoning and coordination of motor outputs)" (313). The objection here is that there is no consideration given to the subjective dimensions of cognition, or the experience of thinking. But Walsh also addresses points of tension between phenomenological and "extentionist" approaches to thinking. He writes: "The [cognitive enhancement] debate, however, does not adequately integrate important phenomenological insights, and typically presupposes a thoroughgoing functionalism about the mind and cognitive processes. This presupposition is most evident in the extensionist framework for CE (Clark 2007; Levy 2007; Heersmink 2011; Kiran and Verbeek 2010)." Walsh criticizes these approaches, which, following the path set out by Clark and Chalmers, "define the human-artifact relation as a single integrated cognitive system," adding "a defining feature of the extended cognition discourse has been its systematic neglect of consciousness." Walsh's concern is that ignoring the phenomenology of thought risks an uncritical attitude toward enhancements that might undermine the agential character of thinking and with it cognitive virtues such as self-reliance and understanding. Walsh's is very much a phenomenological critique not only of technologies of the mind but also of certain philosophies of cognitive technologies of the mind that neglect to account for the thing they are altering, consciousness, in its most salient aspect, intentional experience.

Qaurooni and Ekbia (2017) apply a phenomenological analysis and critique to a specific human-cognitive artifact relation, namely military unmanned aerial vehicles (drones) and their pilots. Like Walsh, they use a phenomenological analysis to question functionalism's adequacy in assessing the impact of this artifact or suite of artifacts on the human sensorium. They extend their analysis from the case study of drone-pilot interface, drawing on first-hand testimony, to broader conclusions concerning cognitive enhancement. While Walsh's focus was on the phenomenology of thought, Qaurooni and Ekbia focus on embodiment. They argue that the dominance of the functionalist approach to embodiment in the cognitive enhancement literature is indifferent to the differences in bodies (human-machine hybrids) beyond being better or worse for attaining a specified aim. They accuse this form of thinking, which pervades the cognitive enhancement debate, of falling victim to an automaticity-autonomy or means-end binary. Subsequently, they consider the ethical, political, and indeed epistemological - what is this doing to our notion of thinking - fallouts of this dominant paradigm and seek to undermine it.

Cassou-Noguès (2017) also examines the social impact of cognitive enhancement. He interrogates the turn, associated with Buchanan (2011a), from an individual analysis of enhancement to a social or political consideration of the benefits and potential drawbacks, criticizing the social cost-benefit approach that he thinks Buchanan takes. Such an approach would only be adequate in a kind of liberal utopia that does not match any of the actual contexts where the social and political benefits of enhancement are being discussed. As an alternative, Cassou-Noguès urges a narrative approach that considers not only a functionalist cost-benefit analysis, but also the fate of the subject in differing technological environments. Indeed, a common concern running through the 
three broadly phenomenological approaches to cognitive enhancement in this issue (Walsh, Qaurooni and Ekbia, and Cassou-Noguès) is the state of the thinking and embodied subject in the enhancement debate, or more precisely the absence of these considerations, which they seek to identify and rectify.

\section{Conclusion}

The aim of this issue is to continue the effort to broaden the cognitive enhancement debate through the inclusion of perspectives that I've dubbed FE-PHEN-4E. The articles herein demonstrate not only the richness of these approaches, but also the lack of uniformity and often agreement between them. What I think that they do share (often implicitly) is a philosophical heritage that emphasizes careful analyses of the relation between embodied subjects and their surrounding worlds, as well as attention to how those relations are socially, culturally, and technologically mediated. Indeed, one of the important findings of this heritage is that the social, cultural, and technological cannot be separated and analyzed in abstraction from one another. In many instances, mechanisms or institutions of social interaction and cultural objects can and should be considered as technologies and must be included in discussion concerning enhancement or indeed anthropotechnology.

The broadening of the enhancement debate that I have discussed here is programmatic and will hopefully serve to open further avenues of investigation. By way of conclusion, I will briefly indicate one direction this might take and some of the issues that I think demand attention within the wider scope of the enhancement debate. Nor do I think that the relation between the enhancement debate and FE-PHEN-4E is unidirectional. Phenomenology, French epistemology, and 4E approaches can also benefit from engagement with the questions raised in the enhancement debate.

The human environment is and always has been a technological environment. This is a lesson learned above from Leroi-Gourhan and Canguilhem. But humans are not passive is this environment, as creators of technology they not only build their evolutionary niche but also can resist it and actively reshape it and its pressures, albeit without ever fully knowing the future consequences of their constant interventions. These interventions transform the environment, but in doing so also transform human beings themselves. The current debate about enhancement technologies concerns technologies that aim directly at transforming the human being at individual and collective levels and thus facilitating different forms of relations with the environment and its demands. If one thing is key, it is the emphasis on the relationality between the organism, the human, and its environment, concepts like normalcy, health, pathology, and enhancement only have sense against the backdrop of this relationality.

The idea of resistance which we encountered above in the citation from Canguilhem is important to this relationality in various senses. On the one hand, all experience can be characterized as the experience of the resistance of the surrounding world. This resistance is felt in the demands that the world makes on the organism and in the difficulty of carrying out projects qua responses to these demands within the world. Thinking itself should perhaps be understood in these terms. Intentional experience of the world is an experience of the resistance of the world to its being processed purely in terms of information, its resistance to being cognized. This resistance is what gives the 
objects of experience their defining characteristic of standing outside of those experiences and withholding something of themselves. What in Phenomenological parlance is called transcendence. Cognition runs into objects and is routed around them, in other directions, on tangents, or back toward itself; in this way the environment's resistance to cognition is what engenders thought, and creativity. Too much resistance from the world to either the processes of cognition or the motility of the body however lead to the experience of a shrunken milieu, to illness. Conversely, changes to our bodies which are designed to make the world feel suppler to the demands of our cognitive powers, i.e. exhibit less resistance, may inhibit what we value about thinking, while at the same time making our responses to certain environmental demands less arduous. To return to the modafinil example, this is certainly something to be considered when evaluating particular interventions epistemologically, ethically, and socially. In the case of modafinil, there is reason to believe that it facilitates certain forms of cognitive activity while inhibiting others (Mohamed 2014) which we might consider epistemologically virtuous, at least in certain contexts. As philosophers of technology have long pointed out, technological interventions are value-laden. In this case, some cognitive enhancements will facilitate cognitive functions more suited to some environments than others, but those environments are not neutral either, as technological environments they are also value-laden and display affinities for some manners of cognition or thought over others and subsequently for some manners of further intervention over others. These affinities may also not be in line with our understanding of epistemic virtues at an individual or social level. Here the interaction with the enhancement debate can bring into better focus aspects of the phenomenology of thinking, creativity, imagination, distraction, etc. in their relation to epistemic virtue. There may also be evolutionary constraints on the malleability of our intellectual capacities vis-à-vis the surrounding world.

It is here that another sense of resistance becomes relevant, the sense that Canguilhem had in mind when he wrote that humans could use technology to resist the demands of their technological environments and alter those demands. Market economies are composed of technological inventions that make demands upon human intellectual and cognitive capacities. In the literature that I have critically discussed in this introduction, cognitive enhancements are often described as interventions that will allow humans to better adapt to the exigencies of this particular form of technological environment. We should ask here if the pressures of this environment, characterized at the moment by increasing possibilities and ubiquity of human-computer hybridity and interface, increased powers of big data and various forms of AI, and new possibilities for chemical alteration of our bodies, do not lead to a flattening out of cognitive capacities in accordance with the demands of the market environment. This might not be the case of course; a possible retort is that markets prefer diversity to uniformity in both producers and consumers. Buchanan (2011b) makes an anecdotal argument to this effect in relation to sexual preferences and the alteration of physical appearance via genetic engineering. But a preference for diversity was not the case with previous transformations in the economic environment, for example the transition to industrial or later consumer economies, where standardization of both production and consumption was a key characteristic of the social and technological shift. In any case, the increased technological plasticity of our cognitive capacities should perhaps lead us to be critical concerning the effects of market forces on technologically mediated cognitive trends. It 
is interesting to note in this context that the UK Labour Party recently discussed the creation of a shadow (opposition party) ministerial post for Neuro-diversity. The concept of resistance, important to both Canguilhem's analysis of the relation between the normal and the pathological and phenomenological theories of intentional consciousness is but one example of how these areas might contribute to the ongoing debates concerning cognitive enhancement and how these debates might also contribute in turn to our understanding of such fundamental and varied phenomena as illness, normalcy, and even the activity of thinking.

\section{References}

Allouche, S. (2015). From enhancement medicine to anthropotechnology. In D. Meacham (Ed.), Medicine and society, new continental perspectives. Philosophy and medicine 120 (pp. 295-315). Dordrecht: Springer.

Arnaldi, S., Ferrari, A., Gorgoni, G., Meacham, D., and Pustovrh, T. (2016). Better Humans by way of Science and Technology. International Social Research Foundation Bulletin 11, 34-39.

Battleday, R. M., \& Brem, A. K. (2015). Modafinil for cognitive neuroenhancement in healthy non-sleepdeprived subjects: A systematic review. Journal of European Neuropsychopharmacology, 25(11), 18651881.

Besnier, J. M. (2010). Demain les posthumains. Le future a-t-il encore besoin de nous? Paris: Fayard.

Boorse, C. (1977). Health as a theoretical concept. Philosophy of Science, 44, 542-573.

Bostrom, N., \& Sanberg, A. (2009). Cognitive enhancement: Methods, ethics, regulatory challenges. Science and Engineering Ethics, 15(3), 311-341.

Brenninkmeijer, J. \& Zwart, H. (2016). From 'hard' neuro-tools to 'soft' neuro-toys? Refocussing the neuroenhancement debate. Neuroethics. doi:10.1007/s12152-016-9283-6.

Buchanan, A. (2011a). Beyond humanity? The ethics of biomedical enhancement. Oxford: Oxford University Press.

Buchanan, A. (2011b). Better than human: The promise and perils of enhancing ourselves. Oxford: Oxford University Press.

Buller, T. (2013). Neurotechnology, invasiveness and the extended mind. Neuroethics, 6, 593-605.

Canguilhem, G. (2008). Knowledge of life. Translated by S. Geroulanos and D. Ginsburg. New York: Fordham University Press.

Cassou-Noguès, P. (2017). The social impact and the intrusive dimension of enhancement. Phenomenology and the Cognitive Sciences. doi:10.1007/s11097-016-9480-0.

Clark, A. (2007). Re-inventing ourselves: The plasticity of embodiment, sensing, and mind. Journal of Medicine and Philosophy, 32, 263-282.

Clark, A., \& Chalmers, D. (1998). The extended mind. Analysis, 58(1), 7-19.

Daniels, N. (2000). Normal functioning and the treatment-enhancement distinction. Cambridge Quarterly of Healthcare Ethics, 9(3), 309-322.

Fenton, E. (2006). Liberal eugenics and human nature: Against Habermas. The Hastings Center Report, 36(6), $35-42$.

Frank, M. C., Everett, D. L., Fedorenko, E., \& Gibson, E. (2008). Number as a cognitive technology: Evidence from Pirahã language. Cognition, 108, 819-824.

Friedman, R. (2014). A natural fix for ADHD. New York Times, 31 October 2014. Available at: http:/www. nytimes.com/2014/11/02/opinion/sunday/a-natural-fix-for-adhd.html?_r.0. Accessed 22 January 2017

Fritz, N. S., Nadler, R., Manogaran, P., Chong, E. W. J., \& Reiner, P. (2013). Public attitudes toward cognitive enhancement. Neuroethics 7, 173-188. doi:10.1007/s12152-013-9190-Z.

Funk, C., Kennedy, B., \& Sciupac, E. (2016). U.S. Public Wary of Biomedical Technologies to 'Enhance' Human Abilities. Pew Research Center, 1-131.

Goffette, J. (2006). Naissance de l'anthropotechnie. Paris: Vrin.

Habermas, J. (2003). The future of human nature. Oxford: Polity Press.

Heersmink, R. (2011). Defending extension theory: A response to Kiran and verbeek. Philosophy and Technology, 25, 121-128.

Heersmink, R. (2013). A taxonomy of cognitive artifacts: Function, information, and categories. The Review of Philosophy \& Psychology, 4, 1-17. 
Heersmink, R. (2014). The metaphysics of cognitive artefacts. Philosophical Explorations. doi:10.1080 /13869795.2014.910310.

Heersmink, R. (2017). Extended mind and cognitive enhancement: Moral aspects of cognitive artifacts. Phenomenology and the Cognitive Sciences. doi:10.1007/s11097-015-9448-5.

Hildt, E. (2013). Cognitive enhancement: A critical look at the recent debate. In E. Hildt (Ed.), Cognitive enhancement: An interdisciplinary perspective (pp. 1-14). Dordrecht: Springer.

Hinshaw, S., \& Scheffler, R. (2014). The ADHD explosion: Myths, medication, money, and today's push for performance. Oxford: Oxford University Press.

Jerry, J. M., Shirvani, N., \& Dale, R. (2016). Addiction to armodafinil and modafinil presenting with parannoia. Journal of Clinical Psychopharmacology, 36(1), 98-100.

Kingma, E. (2007). What is it to be healthy? Analysis, 67(294), 128-133.

Kiran, A. H., \& Verbeek, P.-P. (2010). Trusting our selves to technology. Knowledge, Technology, and Policy, 23, 409-427. doi:10.1007/s12130-010-9123-7.

Knapton, S. (2015). Smart drug' taken by one in four students really does boost performance. The Telegraph 20 August 2015. http:/www.telegraph.co.uk/news/science/science-news/11812682/Smart-drug-taken-byone-in-four-students-really-does-boost-performance.html. Last accessed 22 Feb 2017.

Ledford, H. (2009). Cognitive enhancement drug may cause addiction. Nature. doi:10.1038/news/.2009.170.

Levy, N. (2007). Rethinking neuroethics in the light of the extended mind thesis. American Journal of Bioethics, 7, 3-11.

Meacham, D. (2015). The subject of enhancement: Augmented capacities, extended cognition, and delicate ecologies of the mind. The New Bioethics, 21(1), 5-19.

Menary, R. (2010). Introduction to the special issue on 4E cognition. Phenomenology and the Cognitive Sciences, 9, 459-463.

ter Meulen, R., Mohammed, A., \& Hall, W. (Eds.). (2017). Rethinking cognitive enhancement. Oxford: Oxford University Press.

Mitch, D. (2004). Education and skill of the British labour force. In R. Floud \& P. Johnson (Eds.), The Cambridge economic history of modern Britain, Industrialisation, 1700-1860 (Vol. I, pp. 332-356). Cambridge: Cambridge University Press.

Mohamed, A. D. (2014). The effects of modafinil on convergent and divergent thinking of creativity: A randomized controlled trial. Journal of Creative Behaviour, 50(4), 1-21.

O'Connor, C., Geraint, R., \& Joffe, H. (2012). Neuroscience in the public sphere. Neuron, 74, 220-226. doi:10.1016/j.neuron.2012.04.004.

Qaurooni, D., \& Ekbia, H. (2017). The "enhanced" warrior: Drone warfare and the problematics of separation. Phenomenology and the Cognitive Sciences. doi:10.1007/s11097-016-9481-z.

Stiegler, B. (2012). On Lights and Shadows in the Digital Age, Keynote Lecture, Digital Inquiry Symposium, University of California, Berkley. 27 April 2012. http://www.cronistas.org/wp-content/uploads/2014/02 /Digital-Inquiry-Bernard-Stiegler-on-Lights-and-Shadows-in-the-Digital-Age.pdf. Last accessed 22 Feb 2017.

Thomas, H. (2015). Narcolepsy medication modafinil is world's first safe 'smart drug'. Guardian 20 August 2015. https://www.theguardian.com/science/2015/aug/20/narcolepsy-medication-modafinil-worlds-firstsafe-smart-drug. Last accessed 30 Feb 2017.

United States Department of Education (2001). NCLB Overview Executive Summary. https://www2.ed. gov/nclb/overview/intro/execsumm.html. Last accessed 20 Feb 2017.

Walsh, P. J. (2017). Cognitive extension, enhancement, and the phenomenology of thinking. Phenomenology and the Cognitive Sciences. doi:10.1007/s11097-016-9461-3.

Zohny, H. (2015). The myth of cognitive enhancement drugs. Neuroethics. doi:10.1007/s12152-015-9232-9.

Zwart H. et al. (2015). NERRI WP3 final report: Presentation and analysis of 60 mutual learning exercises. http://www.nerri.eu/eng/deliverables/deliverable-35-final-report-wp3.aspx; doi:10.13140 /RG.2.1.1034.7282. 